\title{
In Vitro Schistosomicidal Activity of Some Brazilian Cerrado Species and Their Isolated Compounds
}

\author{
Nayanne Larissa Cunha, ${ }^{1}$ Camila Jacintho de Mendonça Uchôa, ${ }^{1}$ Lucas Silva Cintra, ${ }^{1}$ \\ Herbert Cristian de Souza, ${ }^{1}$ Juliana Andrade Peixoto, ${ }^{1}$ Claudia Peres Silva, ${ }^{1}$ \\ Lizandra Guidi Magalhães, ${ }^{1}$ Valéria Maria Meleiro Gimenez, ${ }^{2}$ Milton Groppo, ${ }^{3}$ \\ Vanderlei Rodrigues, ${ }^{4}$ Ademar Alves da Silva Filho, ${ }^{5}$ Márcio Luís Andrade e Silva, ${ }^{1}$ \\ Wilson Roberto Cunha, ${ }^{1}$ Patrícia Mendonça Pauletti, ${ }^{1}$ and Ana Helena Januário ${ }^{1}$
}

\author{
${ }^{1}$ Universidade de Franca, Avenida. Dr. Armando Salles de Oliveira 201, 14404-600 Franca, SP, Brazil \\ ${ }^{2}$ Centro Universitário Claretiano, Rua Dom Bosco 466, 14300-000 Batatais, SP, Brazil \\ ${ }^{3}$ Faculdade de Filosofia, Ciências e Letras, Universidade de São Paulo, Avenida Bandeirantes 3900, \\ 14040-901 Ribeirão Preto, SP, Brazil \\ ${ }^{4}$ Faculdade de Medicina de Ribeirão Preto, Universidade de São Paulo, Avenida Bandeirantes 3900, \\ 14049-900 Ribeirão Preto, SP, Brazil \\ ${ }^{5}$ Departamento Farmacêutico, Universidade Federal de Juiz de Fora, Rua José Lourenço Kelmer, s/no, \\ 36036-900 Juiz de Fora, MG, Brazil
}

Correspondence should be addressed to Ana Helena Januário, anahjanuario@unifran.br

Received 22 April 2012; Revised 7 June 2012; Accepted 8 June 2012

Academic Editor: Jairo Kenupp Bastos

Copyright (C) 2012 Nayanne Larissa Cunha et al. This is an open access article distributed under the Creative Commons Attribution License, which permits unrestricted use, distribution, and reproduction in any medium, provided the original work is properly cited.

\begin{abstract}
Miconia langsdorffi Cogn. (Melastomataceae), Roupala montana Aubl. (Proteaceae), Struthanthus syringifolius (Mart.) (Loranthaceae), and Schefflera vinosa (Cham. \& Schltdl.) Frodin (Araliaceae) are plant species from the Brazilian Cerrado whose schistosomicidal potential has not yet been described. The crude extracts, fractions, the triterpenes betulin, oleanolic acid, ursolic acid and the flavonoids quercetin 3-O- $\beta$-D-rhamnoside, quercetin 3-O- $\beta$-D-glucoside, quercetin 3-O- $\beta$-D-glucopyranosyl-(1-2)$\alpha$-L-rhamnopyranoside and isorhamnetin 3-O- $\beta$-D-glucopyranosyl-(1-2)- $\alpha$-L-rhamnopyranoside were evaluated in vitro against Schistosoma mansoni adult worms and the bioactive $n$-hexane fractions of the mentioned species were also analyzed by GCMS. Betulin was able to cause worm death percentage values of $25 \%$ after $120 \mathrm{~h}$ (at $100 \mu \mathrm{M}$ ), and $25 \%$ and $50 \%$ after 24 and $120 \mathrm{~h}($ at $200 \mu \mathrm{M})$, respectively; besides the flavonoid quercetin 3-O- $\beta$-D-rhamnoside promoted $25 \%$ of death of the parasites at $100 \mu \mathrm{M}$. Farther the flavonoids quercetin 3-O- $\beta$-D-glucoside and quercetin 3- $O-\beta$-D-rhamnoside at $100 \mu \mathrm{M}$ exhibited significantly reduction in motor activity, $75 \%$ and $87.5 \%$, respectively. Biological results indicated that crude extracts of $R$. montana, $S$. vinosa, and M. langsdorffii and some $n$-hexane and EtOAc fractions of this species were able to induce worm death to some extent. The results suggest that lupane-type triterpenes and flavonoid monoglycosides should be considered for further antiparasites studies.
\end{abstract}

\section{Introduction}

Schistosomiasis, caused by trematode flatworms of the genus Schistosoma, is one of the most significant, neglected tropical diseases in the world. This disease still displays significant values of prevalence and morbidity, affecting more than 200 million people worldwide and resulting in as many as 280,000 deaths each year with over 779 million people at risk of infection, despite the great advances in treatment and prevention [1-3]. Praziquantel (PZQ) and oxamniquine are the drugs that are currently available for the treatment of schistosomiasis. However, low cure rates and treatment failure following PZQ administration have been reported in patients [4]. The Brazilian savanna, known as Cerrado, comprises a very rich and characteristic flora that covers more than 2 million square kilometers of Brazilian inland. 
It is a biome that is even more threatened than the Amazon rainforest $[5,6]$. Cerrado is the world's most biodiverse savanna, with high degree of endemism and very high rate of environmental loss, thus regarded as a biodiversity hotspot [7]. This large biodiversity puts the country in a strategic position for the development of rational and sustained exploration of new metabolites of therapeutic value [8]. The use of online techniques has assisted in the rapid identification of active compounds in Cerrado species. As an example we can cite the online identification of chlorogenic acids, sesquiterpene lactones, and flavonoids in the Brazilian Cerrado species Lychnophora ericoides by HPLC-DAD-MS and HPLC-DAD-MS/MS [9]. Moreover, the literature lacks reports on the chemical composition of the selected species, namely Roupala montana Aubl. (Proteaceae), Struthanthus syringifolius (Mart.) (Loranthaceae), and Schefflera vinosa (Cham. \& Schltdl.) Frodin (Araliaceae). Nevertheless, isolation of triterpenes, saponins, and caffeoylquinic acid derivatives from Schefflera and of terpenes, lignans, flavonoids, carbohydrates, fatty acids, amides, phenylpropanoids, tannins, and alkaloids from Struthanthus has been reported [10-14]. Miconia langsdorffii Cogn. (Melastomataceae) has been described to display antileishmanial activity, and isolation of the triterpenes ursolic acid and oleanolic acid from this plant species has been reported [15]. As part of our continuing interest in Brazilian Cerrado species with a view to finding out schistosomicidal agents and new drugs with action against Schistosoma species [16-20], we now report on the evaluation of the schistosomicidal activity of the extracts and fractions obtained from $M$. langsdorffi, R. montana, S. syringifolius, and S. vinosa, as well as on the activity of the isolated compounds betulin (1), oleanolic acid (2), ursolic acid (3), quercetin 3 - $O$ - $\beta$-D-glucoside (4), quercetin 3-O- $\beta$-D-glucopyranosyl(1-2)- $\alpha$-L-rhamnopyranoside (5), isorhamnetin 3-O- $\beta$-Dglucopyranosyl-(1-2)- $\alpha$-L-rhamnopyranoside (6), quercetin 3-O- $\beta$-D-rhamnoside (7).

\section{Material and Methods}

2.1. General. ${ }^{1} \mathrm{H}$ and ${ }^{13} \mathrm{C}$ NMR spectra were recorded in pyridine- $d_{5}$ for triterpenes and DMSO- $d_{6}$ for flavonoids using TMS as internal standard. Both analytical and preparative HPLC separation analyses were carried out on a Shimadzu LC-6AD system equipped with a degasser DGU20A5, a UV-VIS detector SPD-20A series, a communication bus module CBM-20A, and a Reodyne manual injector. Separations of the micromolecules were accomplished on a Shimadzu Shim-pack ODS (particle diameter $5 \mu \mathrm{m}, 250 \times$ $4.60 \mathrm{~mm}$, and $250 \times 20 \mathrm{~mm}$ ) columns equipped with a pre-column of the same material. The $\mathrm{MeOH}$ used in the experiments was HPLC grade, J. T. Baker. Ultrapure water was obtained by passing redistilled water through a Direct-Q UV3 system from Millipore.

2.2. Plant Material. The aerial parts of Roupala montana Aubl. (Proteaceae) and Schefflera vinosa (Cham. \& Schltdl.) Frodin (Araliaceae) were collected in Luis Antonio, State of
São Paulo, Brazil, in May 2008; Miconia langsdorffii Cogn. (Melastomataceae) was collected in Serra Azul, State of São Paulo, Brazil, in March 2009; and Struthanthus syringifolius (Mart.) (Loranthaceae) was collected in Itamarandiba, State of Minas Gerais, Brazil, in October 2009. The materials were identified by Prof. V. M. M. Gimenez and Prof. M. Groppo. Vouchers specimens (SPFR12166, SPFR12167 SPFR12288, and SPFR12171, resp.) were deposited in the Herbarium of Faculdade de Filosofia Ciências e Letras de Ribeirão Preto, University of São Paulo, Brazil (Herbarium SPFR).

2.3. Extraction and Isolation. The aerial parts of M. langsdorffii $(0.5 \mathrm{~kg}), R$. montana $(0.9 \mathrm{~kg}), S$. syringifolius $(1.5 \mathrm{~kg})$, and $S$. vinosa $(0.5 \mathrm{~kg})$ were powdered and exhaustively extracted by maceration at room temperature using $\mathrm{EtOH}$ for the three former plants, while $\mathrm{EtOH} / \mathrm{H}_{2} \mathrm{O} 8: 2(\mathrm{v} / \mathrm{v})$ was employed for S. vinosa. After filtration, the solvent was removed under reduced pressure, yielding $7.8 \mathrm{~g}, 24 \mathrm{~g}, 39 \mathrm{~g}$, and $31 \mathrm{~g}$ of crude extract from the above mentioned plants, respectively. The crude extracts of $R$. montana (RM, $30 \mathrm{~g}$ ), S. syringifolius (SS, $20 \mathrm{~g})$, and S. vinosa (SV, $30 \mathrm{~g}$ ) were then dissolved in $\mathrm{MeOH} / \mathrm{H}_{2} \mathrm{O} 2: 8(\mathrm{v} / \mathrm{v})$ and successively partitioned with $n$ hexane, EtOAc, and $n$-BuOH. After solvent removal, each partition phase furnished $4.0 \mathrm{~g}, 5.9 \mathrm{~g}, 10.3 \mathrm{~g}$, and $5.1 \mathrm{~g}$ of material for R. montana; $5.3 \mathrm{~g}, 2.9 \mathrm{~g}, 3.1 \mathrm{~g}$, and $3.2 \mathrm{~g}$ for S. syringifolius; and $3.9 \mathrm{~g}, 7.0 \mathrm{~g}, 15.5 \mathrm{~g}$, and $2.8 \mathrm{~g}$ for $S$. vinosa. The $n$-hexane fractions $(200 \mathrm{mg})$ of each extract were chromatographed over silica and Florisil $(1: 1, \mathrm{w} / \mathrm{w}, 8 \mathrm{~g})$ using $\mathrm{CH}_{2} \mathrm{Cl}_{2}$ as eluent, to afford three major fractions for each species, which were then analyzed by GC-MS. Besides, the $n$-hexane fraction of $S$. vinosa $(\mathbf{S V}-\mathbf{1})$ was purified by column chromatography over silica gel $60(0.063-0.200 \mathrm{~mm}$, Merck) using $n$-hexane and EtOAc as eluents, which yielded compound 1 from fractions 32-33 ( $n$-hexane/EtOAc $7: 3$ $(\mathrm{v} / \mathrm{v}) ; 42 \mathrm{mg})$. On the other hand the EtOAc fraction of $S$. vinosa (SV-2) was purified by semipreparative reverse phase HPLC using $\mathrm{MeOH} / \mathrm{H}_{2} \mathrm{O} / \mathrm{AcOH}$ (45:54.9:0.1, v/v/v), UV detection at $254 \mathrm{~nm}$, and flow rate $9 \mathrm{~mL} / \mathrm{min}$, furnishing compound $7(7.9 \mathrm{mg})$. In a previous study, our research group had fractioned the crude extract of $M$. langsdorffii (ML, 6.7 g) and obtained six fractions as follows: ML-1: $n$ hexane/EtOAc $75: 25$ (v/v), ML-2: $n$-hexane/EtOAc $50: 50$ (v/v), ML-3: EtOAc, ML-4: AcOEt/EtOH 75 : 25 (v/v), ML-5: AcOEt/EtOH 50:50 (v/v), and ML-6: EtOH [15]. Fraction ML-2 (500 mg) was the most active in the schistosomicial assay, and it was chromatographed over Celite and Norit (3:1, w/w, $60 \mathrm{~g})$ using EtOAc as eluent. The resulting solid amorphous material was dissolved in $\mathrm{MeOH} / \mathrm{H}_{2} \mathrm{O}$ 85:15 $(\mathrm{v} / \mathrm{v})$ and subsequently submitted to semi-preparative RPHPLC purification using $\mathrm{MeOH} / \mathrm{H}_{2} \mathrm{O} / \mathrm{AcOH}$ (85 : 14.9 : 0.1 , $\mathrm{v} / \mathrm{v} / \mathrm{v})$, UV detection at $220 \mathrm{~nm}$, and flow rate $9 \mathrm{~mL} / \mathrm{min}$, leading to compounds 2 (25 mg) and 3 (75 mg). The EtOAc fraction from R. montana (RM-2) followed to semipreparative reverse phase HPLC purification, the analytical conditions were a mobile phase gradient consisting of $\mathrm{MeOH} / \mathrm{H}_{2} \mathrm{O} / \mathrm{AcOH}$ (47:52.9:0.1, v/v/v), UV detection at $254 \mathrm{~nm}$, and a flow rate of $5 \mathrm{~mL} / \mathrm{min}$, yielding compound 4 (5.0 mg). Similarly, the $n-\mathrm{BuOH}$ fraction (RM-3) was submitted to semi-preparative reverse phase HPLC under 
TABLE 1: CG/MS identification of the main chemical constituents of the $n$-hexane fractions of R. montana (RM-1), S. syringifolius (SS-1), and $S$. vinosa $(\mathbf{S V}-\mathbf{1})$.

\begin{tabular}{|c|c|c|c|}
\hline Source/compound & $\mathrm{M}^{+}$ & $t_{R}(\min )$ & Concentration (\%) \\
\hline \multicolumn{4}{|l|}{ R. montana (RM-1) } \\
\hline Ethyl pentadecanoate & 270 & 29.935 & 8.89 \\
\hline Fytol & 296 & 33.653 & 17.91 \\
\hline Squalene & 410 & 52.799 & 4.18 \\
\hline$\gamma$-tocopherol & 416 & 60.342 & 11.71 \\
\hline Lupeol & 426 & 72.546 & 8.05 \\
\hline$\beta$-amyrin & 426 & 70.015 & 1.34 \\
\hline$\alpha$-amyrin & 426 & 72.230 & 0.76 \\
\hline$n$-tetracontane & 619 & 51.188 & 3.85 \\
\hline \multicolumn{4}{|l|}{ S. syringifolius (SS-1) } \\
\hline Methyl palmitate & 270 & 5.842 & 0.30 \\
\hline$n$-heneicosane & 296 & 9.437 & 2.74 \\
\hline$n$-nonacosane & 408 & 11.562 & 13.57 \\
\hline Clionasterol & 414 & 27.655 & 1.21 \\
\hline Lupeol & 426 & 34.065 & 22.03 \\
\hline$\beta$-amyrin & 426 & 31.128 & 12.75 \\
\hline$\alpha$-amyrin & 426 & 33.706 & 5.04 \\
\hline 9,19-ciclolanostan-24-en-3-ol & 426 & 31.883 & 1.74 \\
\hline$\beta$-friedelanol & 428 & 38.254 & 10.29 \\
\hline 9,19-ciclolanostan-3-ol, 24-methylene & 440 & 33.456 & 1.96 \\
\hline$\alpha$-amyrin acetate & 468 & 35.235 & 1.41 \\
\hline Lupeol acetate & 468 & 35.680 & 9.87 \\
\hline$n$-tetracontane & 619 & 14.624 & 3.08 \\
\hline \multicolumn{4}{|l|}{ S. vinosa $(\mathrm{SV}-\mathbf{1})$} \\
\hline Spathulenol & 220 & 18.130 & 7.84 \\
\hline Ethyl palmitate & 284 & 32.450 & 4.57 \\
\hline Stigmasterol & 412 & 63.660 & 3.28 \\
\hline Sitosterol & 414 & 65.045 & 1.39 \\
\hline Lupenone & 424 & 66.225 & 1.33 \\
\hline Lupeol & 426 & 67.015 & 27.91 \\
\hline
\end{tabular}

the same conditions, providing compounds $5(29.0 \mathrm{mg})$ and 6 (12.0 mg).

2.4. GC-MS Analysis. A Shimadzu QP-2010 gas chromatograph equipped with HP-1 or DB-17MS capillary columns $(30 \mathrm{~m} \times 0.25 \mathrm{~mm}$ i.d. $\times 0.25 \mu \mathrm{m}$ film thickness $)$ coupled to a mass spectrometer was employed. EI mass spectra were recorded at $70 \mathrm{eV}$. Conditions: for $S$. vinosa $n$-hexane fraction (SV-1): HP-1 column, injector $250^{\circ} \mathrm{C}$; temperature program $100-290^{\circ} \mathrm{C}$ at $3^{\circ} \mathrm{C} / \mathrm{min}$, followed by 20 -min isotherm; split ratio $1: 30$; carrier gas $\mathrm{He}$ at $1.10 \mathrm{~mL} / \mathrm{min}$ flow rate. For $R$. montana $n$-hexane fraction (RM-1): DB-17MS column, injector $250^{\circ} \mathrm{C}$; temperature program $100-290^{\circ} \mathrm{C}$ at $3^{\circ} \mathrm{C} / \mathrm{min}$, followed by 20 -min isotherm; split ratio $1: 20$; carrier gas $\mathrm{He}$ at $1.10 \mathrm{~mL} / \mathrm{min}$ flow rate. For S. syringifolius $n$-hexane fraction (SS-1): DB-17MS column, injector $250^{\circ} \mathrm{C}$; temperature program $120-260^{\circ} \mathrm{C}$ at $3^{\circ} \mathrm{C} / \mathrm{min}$, followed by 5 -min isotherm; then temperature program $260-280^{\circ} \mathrm{C}$ at $2^{\circ} \mathrm{C} / \mathrm{min}$, followed by 9 -min isotherm; then temperature $280-290^{\circ} \mathrm{C}$ at $2^{\circ} \mathrm{C} / \mathrm{min}$, followed by 20 -min isotherm; split ratio $1: 50$; carrier gas $\mathrm{He}$ at $1.40 \mathrm{~mL} / \mathrm{min}$ flow rate. Identification of the constituents was conducted by computer search in the Wiley Mass Spectral Database 7.

2.5. In Vitro Schistosomicidal Assay. The LE (Luis Evangelista) strain of $S$. mansoni was maintained by passage through Biomphalaria glabrata snails and BALB/c mice. After eight weeks, S. mansoni adult worms were recovered under aseptic conditions from mice previously infected with 200 cercariae by perfusion of the livers and mesenteric veins [21]. The worms were washed in Roswell Park Memorial Institute (RPMI) 1640 medium (Invitrogen), kept at $\mathrm{pH}$ 7.5 with HEPES $20 \mathrm{mM}$, and supplemented with penicillin $(100 \mathrm{UI} / \mathrm{mL})$, streptomycin $(100 \mu \mathrm{g} / \mathrm{mL})$, and $10 \%$ bovine fetal serum (Gibco). After washing, two adult worms were transferred to each well of a 24 -well culture plate containing $2 \mathrm{~mL}$ of the same medium and incubated at $37^{\circ} \mathrm{C}$ in a humid atmosphere containing $5 \% \mathrm{CO}_{2}$ prior to use. At $24 \mathrm{~h}$ after incubation, extracts, fractions, and the isolated compounds (1-7) were dissolved in dimetilsulfoxide (DMSO) and added 


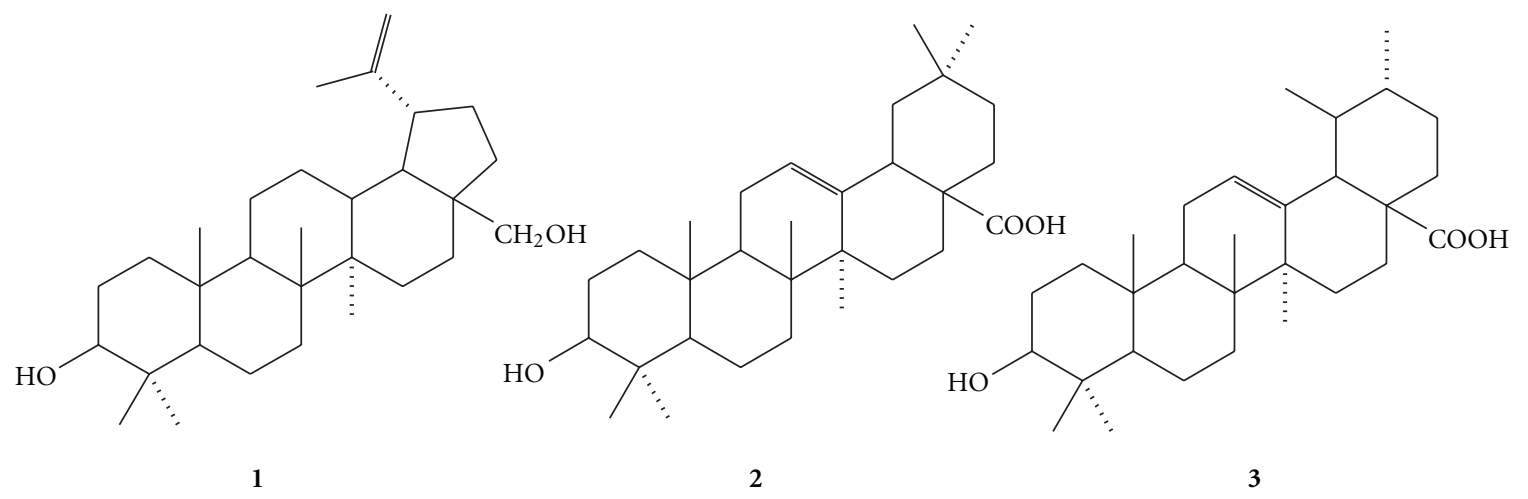<smiles>CCOc1cc(-c2oc3cc(O)cc(O)c3c(=O)c2OCCO)ccc1O</smiles>

$$
\begin{aligned}
& 4 \mathrm{R}_{1}=\mathrm{H} ; \mathrm{R}_{2}=\text { Glu } \\
& 5 \mathrm{R}_{1}=\mathrm{H} ; \mathrm{R}_{2}=\text { Rham-Glu } \\
& 6 \mathrm{R}_{1}=\mathrm{Me} ; \mathrm{R}_{2}=\text { Rham-Glu } \\
& 7 \mathrm{R}_{1}=\mathrm{H} ; \mathrm{R}_{2}=\text { Rham }
\end{aligned}
$$

FIgURE 1: Chemical structures of the isolated compounds.

to RPMI 1640 medium, to give final concentrations of 50, 100 , and $200 \mu \mathrm{g} / \mathrm{mL}$ or $\mu \mathrm{M}$. The parasites were kept for 5 days and monitored each $24 \mathrm{~h}$ to evaluate their general condition. The worms were considered dead when no movement was observed for at least 2 min of examination and no movement at the other observation time points was detected [22]. Quadruplicate measurements were accomplished for each employed concentration and three independent experiments were performed. RPMI 1640 medium and RPMI 1640 with $1 \%$ DMSO (the highest concentration of drug solvent) were used as negative control groups. Praziquantel (PZQ) at $12.5 \mu \mathrm{g} / \mathrm{mL}$ or $12.5 \mu \mathrm{M}$ was used as positive control group. All experiments were authorized by the Ethics Committee for Animal Care of the University of Franca and University of São Paulo, and they were in accordance with the national and international accepted principles for laboratory animal use and care.

\section{Results and Discussion}

The scarcity of studies on the crude extract of M. langsdorffi, R. montana, S. syringifolius, and S. vinosa has encouraged us to accomplish biological and chemical investigations of metabolites belonging to these extracts. The chemical composition of the bioactive $n$-hexane fractions from $\mathrm{EtOH}$ or EtOH/ $\mathrm{H}_{2} \mathrm{O}$ extracts of the aerial parts of R. montana (RM1), S. syringifolius (SS-1), and S. vinosa (SV-1) was initially analyzed by GC-MS, and data are listed in Table 1. It can be noted that the identified compounds mainly belong to the following functional groups: aliphatic esters, hydrocarbons, steroids, and triterpenes. The presence of aliphatic esters is typical of all the investigated hexane fractions. RM-1 contains the largest percent amount of these esters $(8.89 \%)$, followed by SV-1 $(4.57 \%)$, but only trace amounts were detected in SS-1 $(0.30 \%)$. Triterpenes were identified in great quantities in SS-1 (61.39\%), followed by SV-1 (29.24\%), and RM-1 (10.15\%). Steroids were observed in SV-1 (4.67\%) and SS-1 (4.91\%). Hydrocarbons were detected in SS1 (19.39) and RM-1 (8.03\%). Compounds determined in minor quantities were sesquiterpenes, diterpenes, and tocopherol, which were only found in SV-1 (7.84\%), RM1 (17.91\%), and RM-1 (11.71\%), respectively. The spectral profiles of the isolated compounds were in agreement with previously published data, which allowed identification of betulin (1) and quercetin 3-O- $\beta$-D-rhamnoside (7) in S. vinosa [23, 24]; oleanolic (2) and ursolic (3) acids in $M$. langsdorffii $[23,25]$ in addition to quercetin $3-O-\beta$-D-glucoside (4), quercetin 3-O- $\beta$-D-glucopyranosyl(1-2)- $\alpha$-L-rhamnopyranoside (5) and isorhamnetin 3-O$\beta$-D-glucopyranosyl-(1-2)- $\alpha$-L-rhamnopyranoside (6) in $R$. montana (Figure 1) [24, 26]. To the best of our knowledge, this is the first report of the presence of compound 1 in S. vinosa and the occurrence of the flavonoids 4,5 and 6 in $R$. montana. In this study, the in vitro effect of 
TABLE 2: In vitro effects of the crude extract and fractions against S. mansoni adult worms.

\begin{tabular}{|c|c|c|c|c|c|c|c|}
\hline \multirow[t]{2}{*}{ Group } & \multirow[t]{2}{*}{ Incubation period $(\mathrm{h})$} & \multicolumn{3}{|c|}{$\begin{array}{l}\% \text { of dead worms at a given } \\
\text { concentration }(\mu \mathrm{g} / \mathrm{mL})\end{array}$} & \multicolumn{3}{|c|}{$\begin{array}{l}\% \text { reduction in motor activity } \\
\text { at a given concentration }(\mu \mathrm{g} / \mathrm{mL})\end{array}$} \\
\hline & & 50 & 100 & 200 & 50 & 100 & 200 \\
\hline \multirow{2}{*}{ ML } & 24 & 0 & 25 & n.t. & 0 & 75 & n.t. \\
\hline & 120 & 0 & 100 & n.t. & 0 & 0 & n.t. \\
\hline \multirow{2}{*}{ ML-2 } & 24 & 0 & 37.5 & n.t. & 12.5 & 0 & n.t. \\
\hline & 120 & 50 & 62.5 & n.t. & 37.5 & 12.5 & n.t. \\
\hline \multirow{2}{*}{ RM } & 24 & 0 & 0 & 0 & 0 & 0 & 25 \\
\hline & 120 & 0 & 0 & 100 & 0 & 0 & 0 \\
\hline \multirow{2}{*}{ RM-1 } & 24 & 0 & 0 & 0 & 75 & 75 & 25 \\
\hline & 120 & 0 & 100 & 100 & 100 & 0 & 0 \\
\hline \multirow{2}{*}{ RM-2 } & 24 & 0 & 25 & n.t. ${ }^{\mathrm{a}}$ & 0 & 75 & 0 \\
\hline & 120 & 100 & 100 & n.t. & 0 & 0 & 0 \\
\hline \multirow{2}{*}{ RM-3 } & 24 & 0 & 0 & 0 & 0 & 0 & 0 \\
\hline & 120 & 0 & 0 & 0 & 0 & 0 & 0 \\
\hline \multirow{2}{*}{ SS } & 24 & 0 & 0 & 0 & 25 & 100 & 100 \\
\hline & 120 & 0 & 0 & 0 & 50 & 100 & 100 \\
\hline \multirow{2}{*}{ SS-1 } & 24 & 0 & 25 & 25 & 100 & 75 & 75 \\
\hline & 120 & 25 & 25 & 25 & 75 & 75 & 50 \\
\hline \multirow{2}{*}{ SS-2 } & 24 & 0 & 0 & 0 & 0 & 0 & 25 \\
\hline & 120 & 0 & 0 & 0 & 0 & 0 & 25 \\
\hline \multirow{2}{*}{ SS-3 } & 24 & 0 & 0 & 0 & 0 & 0 & 25 \\
\hline & 120 & 0 & 0 & 0 & 0 & 25 & 25 \\
\hline \multirow{2}{*}{ SV } & 24 & 0 & 0 & 0 & 0 & 75 & 100 \\
\hline & 120 & 0 & 25 & 100 & 100 & 100 & 0 \\
\hline \multirow{2}{*}{ SV-1 } & 24 & 0 & 0 & 100 & 25 & 50 & 0 \\
\hline & 120 & 0 & 100 & 100 & 100 & 0 & 0 \\
\hline \multirow{2}{*}{ SV-2 } & 24 & 0 & 25 & 100 & 0 & 25 & 0 \\
\hline & 120 & 0 & 100 & 100 & 0 & 0 & 0 \\
\hline \multirow{2}{*}{ SV-3 } & 24 & 0 & 0 & 0 & 0 & 0 & 0 \\
\hline & 120 & 0 & 0 & 100 & 0 & 0 & 0 \\
\hline \multirow{2}{*}{ Control $^{\mathrm{b}}$} & 24 & 0 & 0 & 0 & 0 & 0 & 0 \\
\hline & 120 & 0 & 0 & 0 & 0 & 0 & 0 \\
\hline \multirow{2}{*}{$1 \%$ DMSO } & 24 & 0 & 0 & 0 & 0 & 0 & 0 \\
\hline & 120 & 0 & 0 & 0 & 0 & 0 & 0 \\
\hline
\end{tabular}

${ }^{\mathrm{a}}$ n.t.: not tested.

${ }^{b}$ RPMI 1640.

PZQ at $12.5 \mu \mathrm{g} / \mathrm{mL}=100 \%$ parasite death on $24 \mathrm{~h}$ of incubation.

the investigated extracts, fractions, and isolated compounds on S. mansoni parasite mortality was evaluated by incubation of the target microorganism with different concentrations and by evaluation of decrease in motor activity of this worm. In all the experiments, the negative control groups remained viable throughout the observation period. On the other hand, parasites belonging to the positive control group (PZQ) caused $100 \%$ parasite death on the first day of incubation. In addition no tegumental damage was observed in adult worms incubated with the evaluated crude extracts, fractions, and isolated compounds. The tegument is extremely important for parasite survival and infection success within the host, and it has been a major target for the development of drugs against Schistosoma [20, 22]. Except for SS, all the studied crude extracts displayed some effect on S. mansoni mortality (Table 2). On the first day of incubation, crude extract ML at a concentration of $100 \mu \mathrm{g} / \mathrm{mL}$ caused $25 \%$ adult worms mortality. In addition, on the fifth day of incubation $100 \%$ parasite mortality was achieved with extract ML at concentration of $100 \mu \mathrm{g} / \mathrm{mL}$ and also with extracts $\mathbf{R M}$ and $\mathbf{S V}$ at concentrations of $200 \mu \mathrm{g} / \mathrm{mL}$. On the other hand extracts SS and SV displayed significant reduction in motor activity at 50, 100 and $200 \mu \mathrm{g} / \mathrm{mL}$. The occurrence of lethal effect on the first 
TABLE 3: In vitro effects of isolated compounds against S. mansoni adult worms.

\begin{tabular}{|c|c|c|c|c|c|c|c|}
\hline \multirow[t]{2}{*}{ Group } & \multirow[t]{2}{*}{ Incubation period (h) } & \multicolumn{3}{|c|}{$\begin{array}{l}\% \text { of dead worms at a given } \\
\text { concentration }(\mu \mathrm{M})\end{array}$} & \multicolumn{3}{|c|}{$\begin{array}{l}\% \text { reduction in motor activity } \\
\text { at a given concentration }(\mu \mathrm{M})\end{array}$} \\
\hline & & 50 & 100 & 200 & 50 & 100 & 200 \\
\hline \multirow{2}{*}{1} & 24 & 0 & 0 & 25 & 0 & 50 & 25 \\
\hline & 120 & 0 & 25 & 50 & 0 & 50 & 0 \\
\hline \multirow{2}{*}{2} & 24 & 0 & 0 & 0 & 0 & 0 & 25 \\
\hline & 120 & 0 & 0 & 0 & 0 & 0 & 25 \\
\hline \multirow{2}{*}{3} & 24 & 0 & 0 & 0 & 25 & 0 & 50 \\
\hline & 120 & 0 & 0 & 0 & 25 & 25 & 50 \\
\hline \multirow{2}{*}{4} & 24 & 0 & 0 & n.t. ${ }^{\mathrm{a}}$ & 50 & 75 & n.t. \\
\hline & 120 & 0 & 0 & n.t. & 50 & 75 & n.t. \\
\hline \multirow{2}{*}{5} & 24 & 0 & 0 & n.t. & 0 & 0 & n.t. \\
\hline & 120 & 0 & 0 & n.t. & 0 & 0 & n.t. \\
\hline \multirow{2}{*}{6} & 24 & 0 & 0 & n.t. & 0 & 25 & n.t. \\
\hline & 120 & 0 & 0 & n.t. & 0 & 0 & n.t. \\
\hline \multirow{2}{*}{7} & 24 & 0 & 0 & n.t. & 75 & 87.5 & n.t. \\
\hline & 120 & 0 & 25 & n.t. & 75 & 87.5 & n.t. \\
\hline \multirow{2}{*}{ Control $^{b}$} & 24 & 0 & 0 & 0 & 0 & 0 & 0 \\
\hline & 120 & 0 & 0 & 0 & 0 & 0 & 0 \\
\hline \multirow{2}{*}{$1 \%$ DMSO } & 24 & 0 & 0 & 0 & 0 & 0 & 0 \\
\hline & 120 & 0 & 0 & 0 & 0 & 0 & 0 \\
\hline
\end{tabular}

a.t.: not tested.

${ }^{b}$ RPMI 1640.

PZQ at $12.5 \mu \mathrm{M}=100 \%$ parasite death on $24 \mathrm{~h}$ of incubation.

treatment day was noted for fractions RM-2, SS-1, SV-2, and ML-2 at a concentration of $100 \mu \mathrm{g} / \mathrm{mL}$; however, on the fifth treatment day, fraction RM-2 prompted $100 \%$ mortality at concentrations of $50 \mu \mathrm{g} / \mathrm{mL}$ and $100 \mu \mathrm{g} / \mathrm{mL}$ and fractions SV1 and SV-2 caused $100 \%$ parasite mortality at concentrations of $100 \mu \mathrm{g} / \mathrm{mL}$ and $200 \mu \mathrm{g} / \mathrm{mL}$. Furthermore fractions RM-1, SS-1, SV-1, and ML-2 promoted considerable reduction in motor activity at the assayed concentrations.

Fractions SV-1and ML-2 fractions were selected for a further purification process, in which they were chromatographed over silica using an $n$-hexane/EtOAc gradient. SV-1 purification readily furnished $\mathbf{1}$. Compounds 2 and 3 were isolated after semi-preparative HPLC of ML-2 [15]. As observed in Table 3, the isolated compounds 2 and $\mathbf{3}$ did not have lethal effects on S. mansoni adult worms, thus showing loss of activity during the phytochemical procedures. On the other hand, betulin (1) at a concentration of $200 \mu \mathrm{M}$ caused $50 \%$ parasite mortality on the fifth day of incubation. In addition, $25 \%$ mortality was verified on the fifth treatment day at a concentration of $100 \mu \mathrm{M}$ and demonstrated $50 \%$ of reduction in motor activity within $24 \mathrm{~h}$. Thus, betulin (1) has also been demonstrated to exert an effect on S. mansoni adult worm mortality. It is noteworthy that the structures of compounds 1, 2, and 3 are quite similar, differing mainly in the presence of a five-membered ring and an alcohol moiety in $\mathbf{1}$ as compared to the existence of a six-membered ring and an acid group in $\mathbf{2}$ and $\mathbf{3}$. Therefore, bearing in mind parasite viability, it is suggested that the presence of the five-membered ring and the alcohol functional group in $\mathbf{1}$ may improve the activity of triterpenes derivatives against $S$. mansoni, since among compounds $\mathbf{1}, 2$, and 3 only compound 1 caused parasite death. However, the action of betulin in vitro against chloroquine resistant (K1) and sensitive (T9-96) Plasmodium falciparum strains has already been assessed, and it was found to be inactive [27]. On the other hand the semi-preparative RP-HPLC study of fractions RM2, RM-3, and SV-2 afforded the flavonoids 4-7. Considering the schistosomicidal activity results of the flavonoids isolated summarized in Table 3, we can observe that only quercetin 3-O- $\beta$-D-rhamnoside (7), also known as quercitrin, was able to cause $25 \%$ parasite death on the fifth day of treatment at a concentration of $100 \mu \mathrm{g} / \mathrm{mL}$. Concerning the reduction of motor activity of the parasites compared with the negative control, the flavonoid monoglycosides 4 and 7 at $100 \mu \mathrm{M}$ exhibited significantly reduction in motor activity of $75 \%$ and $87.5 \%$, respectively. However, flavonoids $\mathbf{5}$ and $\mathbf{6}$ were inactive. Our results related the isolated flavonoids assayed suggest that the monoglycosylation at C-3 position in ring $\mathrm{C}$ increases the reduction in motor activity in S. mansoni adult worm. Previous investigations on the schistosomicidal activity of natural products realized by our research group reveal that aglycone quercetin was not able to kill the worms but exhibited moderately reduced motor activity [28]. However, quercetin was identified as a selective inhibitor of the S. mansoni $\mathrm{NAD}^{+}$catabolizing enzyme (SmNACE), localized to the outer surface (tegument) of the adult parasite 
and presumably involved in the parasite survival by manipulating the host's immune regulatory pathways. These studies identified that the nature of ring $\mathrm{C}$ and the substitution of free hydroxyl groups in rings $\mathrm{A}, \mathrm{B}$, and $\mathrm{C}$ in flavonoids are key structural features for SmNACE inhibition [29].

The mechanism by which the extracts, fractions, and betulin (1) and flavonoids 4 and 7 exert their effects remains unclear. Moreover, as suggested by our results, the lupane-type triterpene and flavonoid monoglycosides should also be considered for further antiprotozoal studies. In summary, chemical investigations of metabolites from the selected species resulted in the isolation and identification of compounds 1-7. Additionally, biological results indicated that crude extracts RM, SV, and ML; fractions RM-1, RM2, SS-1, SV-1, SV-2, and ML-2; the triterpene betulin (1); the flavonoids quercetin $3-O-\beta$-D-glucoside (4); quercetin 3 $O-\beta$-D-rhamnoside (7) are able to induce worm death to some extent as well as to reduce the motor activity of the parasites. Additional chemical studies are in progress in our research group to identify other natural compounds related to schistosomicidal action of the species investigated. The knowledge of chemical composition and schistosomicidal potential of $R$. montana, S. syringifolius, S. vinosa, and M. langsdorffii will provide insight information for the future application of these plants.

\section{Acknowledgments}

The authors are grateful to Fundação de Amparo a Pesquisa do Estado de São Paulo (FAPESP), Coordenadoria de Aperfeiçoamento de Pessoal do Ensino Superior (CAPES), and Conselho Nacional de Desenvolvimento Científico e Tecnológico ( $\mathrm{CNPq}$ ) for fellowships. FAPESP is also acknowledged for financial support (Grants no. 2006/601324, no. 2008/01268-9 and no. 2009/00604-8). The authors also thank Isabel C.C. Turatti for the GC/MS analysis.

\section{References}

[1] Y. Zhang, C. MacArthur, L. Mubila, and S. Baker, "Control of neglected tropical diseases needs a long-term commitment," BMC Medicine, vol. 8, article 67, 2010.

[2] P. Steinmann, J. Keiser, R. Bos, M. Tanner, and J. Utzinger, "Schistosomiasis and water resources development: systematic review, meta-analysis, and estimates of people at risk," Lancet Infectious Diseases, vol. 6, no. 7, pp. 411-425, 2006.

[3] C. R. Caffrey, "Chemotherapy of schistosomiasis: present and future," Current Opinion in Chemical Biology, vol. 11, no. 4, pp. 433-439, 2007.

[4] S. Botros, S. William, O. Hammam, Z. Zídek, and A. Holý, "Activity of 9-(S)-[3-Hydroxy-2-(Phosphonomethoxy) Propyl]Adenine against Schistosomiasis mansoni in Mice," Antimicrobial Agents and Chemotherapy, vol. 47, no. 12, pp. 3853-3858, 2003.

[5] M. G. Ferri, A vegetação de cerrados brasileiros in E. Warming, Lagoa Santa, Universidade de São Paulo, São Paulo, Brazil, 1973.

[6] J. A. Ratter, J. F. Ribeiro, and S. Bridgewater, "The Brazilian cerrado vegetation and threats to its biodiversity," Annals of Botany, vol. 80, no. 3, pp. 223-230, 1997.
[7] N. Myers, R. A. Mittermeler, C. G. Mittermeler, G. A. B. Da Fonseca, and J. Kent, "Biodiversity hotspots for conservation priorities," Nature, vol. 403, no. 6772, pp. 853-858, 2000.

[8] L. A. Basso, L. H. Pereira Da Silva, A. G. Fett-Neto et al., "The use of biodiversity as source of new chemical entities against defined molecular targets for treatment of malaria, tuberculosis, and T-cell mediated diseases-a review," Memorias do Instituto Oswaldo Cruz, vol. 100, no. 6, pp. 475506, 2005.

[9] L. Gobbo-Neto and N. P. Lopes, "Online identification of chlorogenic acids, sesquiterpene lactones, and flavonoids in the Brazilian arnica Lychnophora ericoides Mart. (Asteraceae) leaves by HPLC-DAD-MS and HPLC-DAD-MS/MS and a validated HPLC-DAD method for their simultaneous analysis," Journal of Agricultural and Food Chemistry, vol. 56, no. 4, pp. 1193-1204, 2008.

[10] G. Cioffi, A. Braca, G. Autore et al., "Cytotoxic saponins from Schefflera fagueti," Planta Medica, vol. 69, no. 8, pp. 750-756, 2003.

[11] Y. Li, P. P. H. But, and V. E. C. Ooi, "Antiviral activity and mode of action of caffeoylquinic acids from Schefflera heptaphylla (L.) Frodin," Antiviral Research, vol. 68, no. 1, pp. 1-9, 2005.

[12] Y. Li, R. Jiang, L. S. M. Ooi, P. P. H. But, and V. E. C. Ooi, "Antiviral triterpenoids from the medicinal plant Schefflera heptaphylla," Phytotherapy Research, vol. 21, no. 5, pp. 466470, 2007.

[13] R. Liu, Q. Q. Gu, C. B. Cui et al., "12 2,13 -Dihydroxyolean-3oxo-28-oic a new triterpene, and the known oleanonic acid as a new cell cycle inhibitor from Schefflera venulosa," Chinese Journal of Chemistry, vol. 23, no. 3, pp. 242-244, 2005.

[14] A. C. Guimarães, "Aspectos etnobotânicos e químicos das famílias Loranthaceae e Viscaceae: potencialidades terapêuticas das Ervas-de-passarinho parasitas," Fitos, vol. 2, no. 1, pp. 27-47, 2006.

[15] J. A. Peixoto, M. L. A. E. Silva, A. E. M. Crotti et al., "Antileishmanial activity of the hydroalcoholic extract of Miconia langsdorffi, isolated compounds, and semi-synthetic derivatives," Molecules, vol. 16, no. 2, pp. 1825-1833, 2011.

[16] N. I. De Melo, L. G. Magalhaes, C. E. De Carvalho et al., "Schistosomicidal activity of the essential oil of Ageratum conyzoides L. (Asteraceae) against adult Schistosoma mansoni worms," Molecules, vol. 16, no. 1, pp. 762-773, 2011.

[17] N. A. Parreira, L. G. Magalhães, D. R. Morais et al., "Antiprotozoal, schistosomicidal, and antimicrobial activities of the essential oil from the leaves of baccharis dracunculifolia," Chemistry and Biodiversity, vol. 7, no. 4, pp. 993-1001, 2010.

[18] C. G. Braguine, E. S. Costa, L. G. Magalhães et al., "Schistosomicidal evaluation of Zanthoxylum naranjillo and its isolated compounds against Schistosoma mansoni adult worms," Zeitschrift fur Naturforschung, vol. 64, no. 11-12, pp. 793-797, 2010.

[19] L. G. Magalhães, C. B. Machado, E. R. Morais et al., "In vitro schistosomicidal activity of curcumin against Schistosoma mansoni adult worms," Parasitology Research, vol. 104, no. 5, pp. 1197-1201, 2009.

[20] J. D. Moraes, C. Nascimento, P. O. M. V. Lopes et al., "Schistosoma mansoni: in vitro schistosomicidal activity of piplartine," Experimental Parasitology, vol. 127, no. 2, pp. 357364, 2011.

[21] S. R. Smithers and R. J. Terry, "The infection of laboratory hosts with cercariae of Schistosoma mansoni and the recovery of the adult worms," Parasitology, vol. 55, no. 4, pp. 695-700, 1965. 
[22] T. Manneck, Y. Haggenmüller, and J. Keiser, "Morphological effects and tegumental alterations induced by mefloquine on schistosomula and adult flukes of Schistosoma mansoni," Parasitology, vol. 137, no. 1, pp. 85-98, 2010.

[23] S. B. Mahato and A. P. Kundu, ${ }^{~}{ }^{13} \mathrm{C}$ NMR spectra of pentacyclic triterpenoids," Phytochemistry, vol. 37, no. 6, pp. 1517-1575, 1994.

[24] Y. L. Li, J. Li, N. L. Wang, and X. S. Yao, "Flavonoids and a new polyacetylene from Bidens parviflora willd," Molecules, vol. 13, no. 8, pp. 1931-1941, 2008.

[25] W. R. Cunha, C. Martins, D. Da Silva Ferreira, A. E. Miller Crotti, N. P. Lopes, and S. Albuquerque, "In vitro trypanocidal activity of triterpenes from Miconia species," Planta Medica, vol. 69, no. 5, pp. 470-472, 2003.

[26] A. Hasler, G. A. Gross, B. Meier, and O. Sticher, "Complex flavonol glycosides from the leaves of Ginkgo biloba," Phytochemistry, vol. 31, no. 4, pp. 1391-1394, 1992.

[27] J. C. Steele, D. C. Warhurst, G. C. Kirby, and M. S. Simmonds, "In vitro and in vivo evaluation of betulinic acid as an antimalarial," Phytochemistry, vol. 31, no. 4, pp. 1391-1394, 1992.

[28] C. G. Braguine, C. S. Bertanha, U. O. Gonçalves et al., "Schistosomicidal evaluation of flavonoids from two species of Styrax against Schistosoma mansoni adult worms," Pharmaceutical Biology, vol. 50, no. 7, pp. 925-929, 2012.

[29] I. Kuhn, E. Kellenberger, F. Said-Hassane et al., "Identification by high-throughput screening of inhibitors of Schistosoma mansoni NAD + catabolizing enzyme," Bioorganic and Medicinal Chemistry, vol. 18, no. 22, pp. 7900-7910, 2010. 


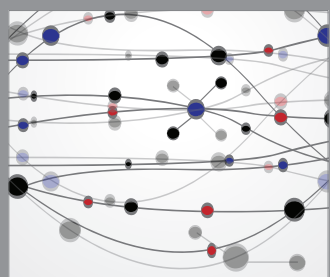

The Scientific World Journal
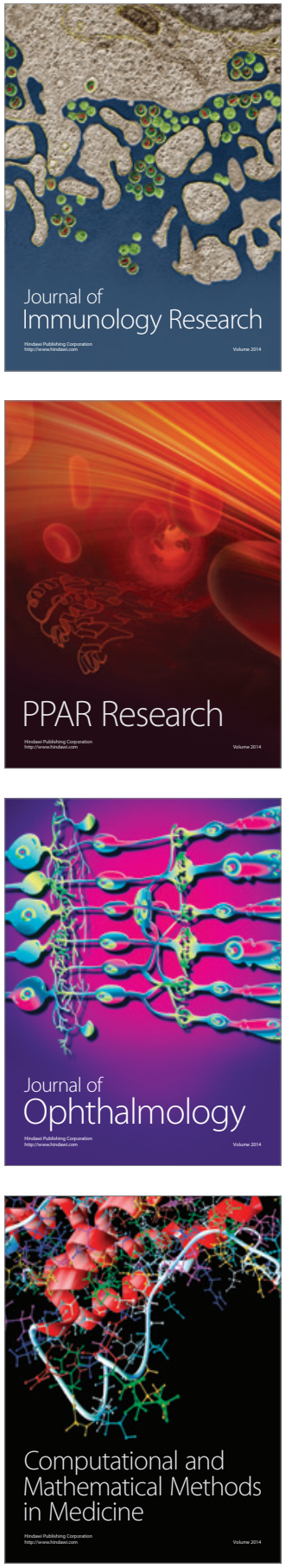

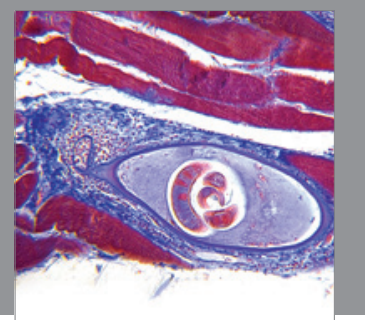

Gastroenterology

Research and Practice
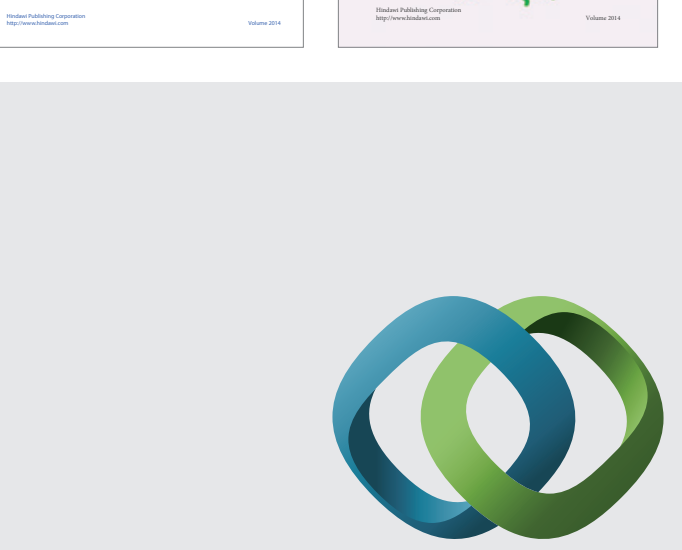

\section{Hindawi}

Submit your manuscripts at

http://www.hindawi.com
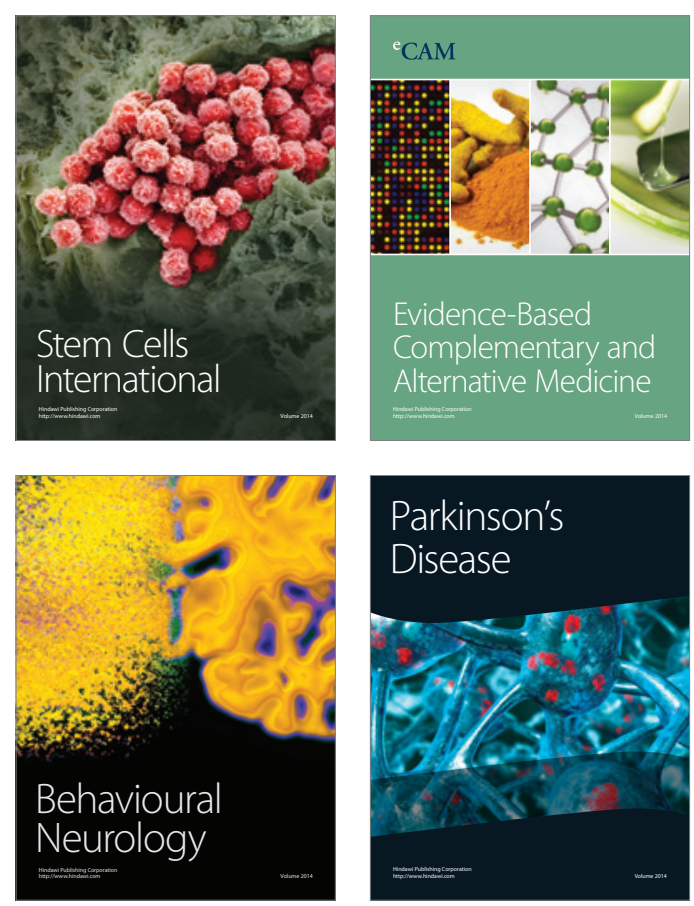

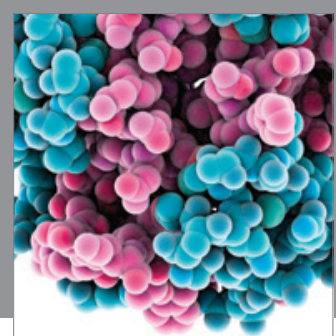

Journal of
Diabetes Research

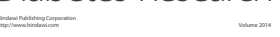

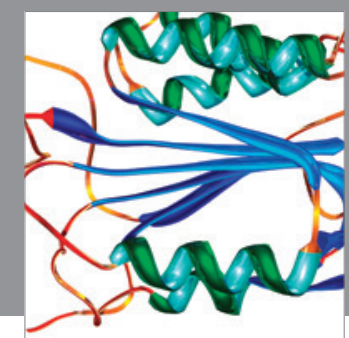

Disease Markers
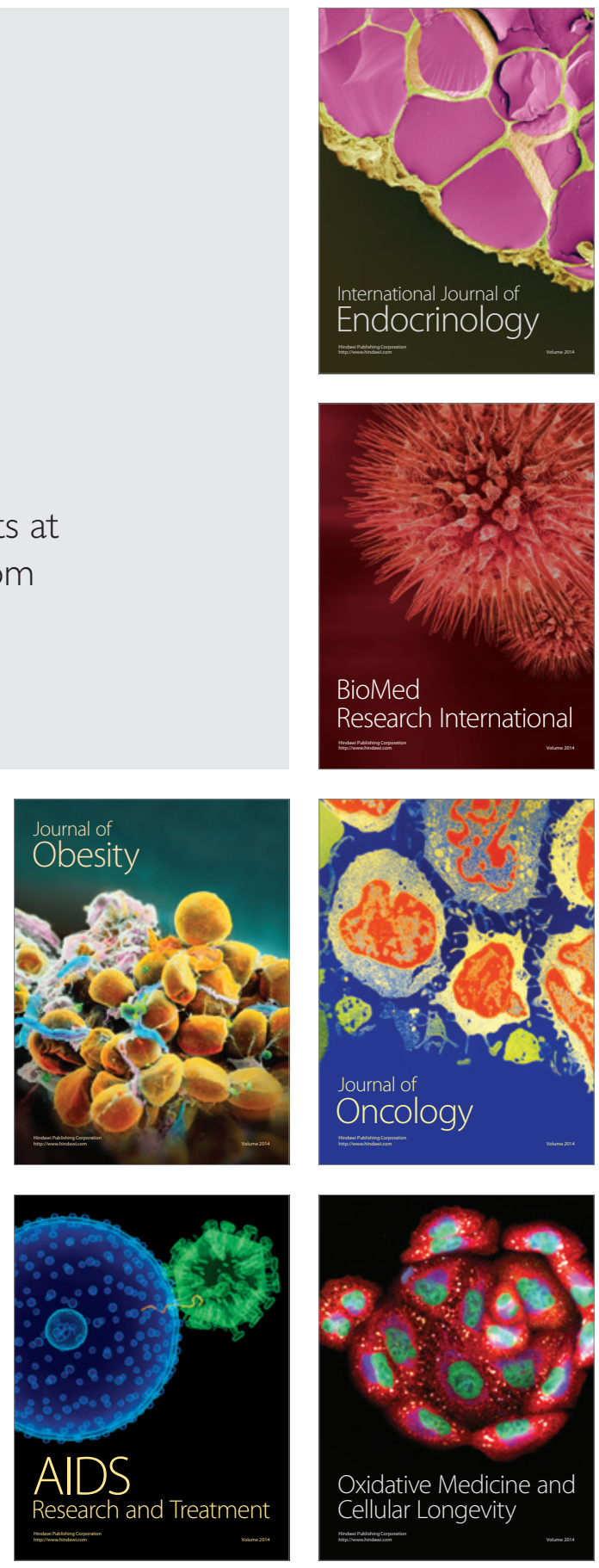